ISSN electrónico: 2172-9077

https://doi.org/10.14201/fjc20171595108

\title{
ANÁLISIS DEL CONSUMO INFANTIL DE TV, VIDEOJUEGOS E INTERNET: DIFERENCIAS EN FUNCIÓN DEL SEXO EN LA SELECCIÓN DE CONTENIDOS AUDIOVISUALES
}

\section{Analysis of Children Consumption of TV, Videogames and the Internet: Differences Based on Gender in their Selection of Audiovisual Content}

\author{
Dra. Beatriz FEIJOO FERNÁNDEZ \\ Profesora investigadora Universidad de Los Andes, Chile \\ E-mail: bfeijoo@uandes.cl \\ (D) orcid.org/0000-0001-5287-3813 \\ Dra. Aurora GARCÍA GONZÁLEZ \\ Profesora titular Universidad de Vigo, España \\ E-mail: auroragg@,uvigo.es \\ (iD) orcid.org/0000-0003-3757-9047
}

Fecha de recepción del artículo: 19/04/2017

Fecha de aceptación definitiva: 15/10/2017

\begin{abstract}
RESUMEN
Bajo una estrategia de atraer públicos diversos, la industria audiovisual ha ido fragmentando su oferta de contenidos en función de varios criterios, entre ellos el de género. En esta investigación se quiso comprobar si estas distinciones se ven reflejadas en la selección de contenidos por parte de los niños ante distintas pantallas (TV, videojuegos, internet). Para esta investigación se recurrió a la metodología cuantitativa de la encuesta autoadministrada entre individuos de 11 a 12 años que cursaban $6^{\circ}$ de primaria repartida en 77 colegios públicos y privados de Galicia, lo que permitió acceder a una muestra de 2200 escolares. De los datos recogidos y analizados se pudo corroborar que los niños optan por contenidos totalmente diferentes según su sexo, a excepción de internet, medio en el que sus preferencias tienden a confluir.

Palabras clave: consumo; contenidos; niños; sexo; pantallas.
\end{abstract}

\begin{abstract}
Under a strategy to attract diverse audiences, the audiovisual industry has been fragmenting its content based on several criteria, including the gender. In this sense, this research aims to verify if these distinctions are reflected in the children's content selection in relation with different screens (TV, videogames and the internet). To cope with this research, we selected a quantitative analysis using the technique of the questionnaire that was distributed among students of 6th year primary school, who are between 11 and 12 years to finally access to a sample of 2200 individuals from 77 public and private Galician schools. Thanks to this data, we could corroborate that children choose completely different content according to their gender, excepting internet, media in which their preferences tend to converge.
\end{abstract}

Key words: consumption; content; children; gender; screens. 


\section{INTRODUCCIÓN}

Esta investigación sobre la influencia del género en el consumo de contenidos audiovisuales durante la infancia parte de las conclusiones de una tesis doctoral (2015) que profundizaba en los principales usos que los escolares gallegos hacían de determinadas pantallas (televisión, videojuegos e internet). Entre los resultados, se hallaron significativas diferencias en cuanto al tiempo y contenidos consumidos (especialmente en televisión y videojuegos) según el sexo del niño. Este estudio se centra en conocer de forma concreta qué diferencias existen entre las preferencias de contenidos a los que acceden a través del televisor, videoconsola e internet según se trate de niño o niña.

\section{EL REFLEJO DE LA IDENTIDAD DE GÉNERO EN MEDIOS DE COMUNICACIÓN Y PANTALLAS}

En esta investigación cuando se habla de género se alude a todos los aspectos culturales que rodean la construcción de las funciones sociales del hombre y de la mujer. Y cuando se habla de sexo se hace referencia a la dotación biológica de cada persona. Y se opta por una perspectiva antropológica que toma en consideración tanto la igualdad como la diferencia. Se parte de la idea de que hombre y mujeres son seres naturalmente diversos, una diferencia que no resulta negativa en tanto en cuanto no se convierta en una imposición arbitraria (Burggraf, 2004). Es en este contexto donde surge el concepto de «perspectiva de igualdad de género» con el que se defiende la participación de hombres y mujeres en todas las esferas de la vida, siempre que esta «meta justa» que se pretende conseguir «a niveles de gobierno político, empresarial, cultural, social y familiar [...] incluya el derecho a ser diferentes» (Burggraf, 2004, p. 30). Un aspecto fundamental de esta perspectiva de género resulta la búsqueda por superar «el androcentrismo de las ciencias sociales que produjo una invisibilidad de la mujer en la historia» (Rodríguez Dorantes, 1997, p. 2).

Cada persona al nacer ya es considerada dentro de un género en función de su naturaleza, lo que condiciona su futuro comportamiento. Es lo que García Guardia y Marcos Molano (2004) definen como roles masculinos/femeninos. Se trata de pautas aprobadas socialmente que se heredan y se asimilan desde niños y que se repiten de forma inconsciente:

En esta etapa de la infancia las personas interiorizan progresivamente las normas de conducta propias de su género, para poder actuar conforme a ellas. Toman conciencia del concepto género, al diferenciar a qué juegan los chicos y a qué las chicas, utilizando como referencia las personas de su entorno familiar, social, educativo, e incluso personajes televisivos. (Martínez Reina y Vélez Cea, 2009, p. 138).

Esta asunción de roles puede implicar el riesgo de caer en simplificaciones con la creación de estereotipos que imponen una imagen forzada de lo que es femenino y masculino, «un refuerzo de prejuicios y convicciones sobre los objetos, las clases sociales y las instituciones» (García Guardia y Marcos Molano, 2004, p. 5).

Este proceso de asimilación no sería posible sin el papel de los agentes culturales destacando desde este campo de investigación el papel jugado por los medios de comunicación y las pantallas, cuya influencia es igual o superior que la de resto de agentes sociales (familia, escuela, grupos de iguales...) sobre todo en la etapa infantil y adolescente (Espinar, 2007; Medrano, Aierbe y Orejudo, 2009). 
Coincidiendo con Espinar (2006), para este análisis se asume que los medios de comunicación desempeñan una función socializadora, «con especial relevancia en el caso de la socialización de género» (2006, p. 3). Por ello, el consumo de medios no puede considerarse como un simple mercado de ocio y entretenimiento, sino que se trata de uno de los grandes «enculturizadores de la sociedad» (Medrano, et al., 2009).

Del mismo modo que Martínez-Reina y Vélez concluyen que los juguetes carecen de género:

Es la cultura y la sociedad quien los etiqueta para un sexo u otro. El niño
y la niña necesitan lo mismo para su desarrollo y educación. Por ejemplo,
la muñeca no es juguete femenino, sino que es una herramienta útil para
desarrollar aptitudes humanitarias. Didácticamente los juguetes deben
considerarse aptos tanto para el niño como para la niña. (2009, p. 143).

Se plantea que los contenidos ofrecidos a través de las diversas pantallas tampoco tienen género. Es la propia industria del entretenimiento la que se encarga de clasificar los contenidos siguiendo una estrategia clara de fragmentación de audiencias. Así, por ejemplo, las corporaciones audiovisuales diseñan el perfil de sus cadenas segmentando según el sexo de sus espectadores al ofertar canales para un público femenino (Nova, Divinity) y otros para el masculino (Mega, Energy) o al clasificar los videojuegos en «azules»y «rosas» (Márquez, 2013). Como destacan Medrano et al. «existen autores (Coyne y Archer, 2004; Hargreaves y Tiggemann, 2004) que defienden la exposición de contenidos diferenciados para atraer a las mujeres y a los hombres en función de lo que socialmente preocupa a cada uno de los sexos» (2009, p. 296).

Por tanto, sí que se puede considerar que las pantallas (por lo menos televisión y videojuegos) establecen diferencias de género al presentar sus contenidos al público. Consecuentemente se produce una relación entre consumo e identidad de género, lo que no significa que la audiencia no pueda elegir libremente qué contenidos ver por encima de esta clasificación de género.

Un porcentaje importante de las investigaciones que relacionan el género y los medios de comunicación se centra en el estudio concreto de televisión. En este campo, Medrano et al. (2009) diferenciaron dos líneas fundamentales de trabajo, una vinculada al análisis de las diferencias por sexo en cuando al perfil de consumo, y otra focalizada en la transmisión y/o percepción de estereotipos masculinos/femeninos en los programas televisivos.

Esta investigación en concreto se incluiría en la primera línea de trabajo, pero aborda además otras pantallas de la televisión. Igualmente coincide con algunos resultados de otras investigaciones previas (Martínez-Reina y Vélez, 2005; Medrano, et al., 2009; Del Moral, Villalustre y Neira, 2010; Márquez, 2013) en las que destaca una diferenciación clara por sexos en el consumo de contenidos televisivos o de videojuegos.

En la segunda línea de trabajo, Espinar $(2006,2007)$, gracias a su análisis de características estereotipadas de hombres y mujeres en la programación televisiva, aportó algunos datos interesantes, como una mayor presencia masculina entre los protagonistas, con mayor habilidad para las cuestiones físicas y limitados para la expresión de sus sentimientos. Se va reduciendo el porcentaje de programas con personajes exclusivamente masculinos conforme más actuales sean. En los casos en que las mujeres ejerzan de protagonistas únicas de los programas, «es mayor la probabilidad de que representen edades tempranas -infantilización de las protagonistas- y que se caractericen por poseer poderes mágicos o sobrenaturales» (2007, p. 133). 
Más específicamente, Belmonte y Guillamón (2008) se centraron en analizar cómo se representaba la identidad de género en aquellas series de televisión ('Los Hombres de Paco', 'El Comisario', 'Aída', 'Aquí no hay quién viva', 'Los Simpson', 'Los Serrano', 'Mis adorables vecinos') que habitualmente consume el público joven para comprobar que difunden una representación de los géneros «dicotomizada y estereotípica» tanto en el contexto laboral como personal.

Pese a su aparente pátina de modernidad, desenfado, inocuidad, frescura o incluso transgresión en algunos casos, en lo referente al género estos productos culturales siguen siendo portadores de discursos que reproducen la desigualdad en la representación de lo femenino y lo masculino. (2008, p. 120).

Aun así, son varios los autores que concluyen que la presencia de estereotipos de género es más evidente y sucede con más intensidad en la publicidad que en la programación televisiva (Medrano, et al., 2009; Espinar, 2006, 2007):

Predominan en las pantallas los anuncios de alto nivel de estereotipo; ya sean masculinos o femeninos, que van a inducir al aprendizaje de valores como diversión y competición, riesgo y agresividad para el caso de los chicos, y de valores como belleza y apariencia, el cuidado de otros o la atención al hogar en el caso de las niñas. Unos estereotipos contra los que luego se intenta luchar a nivel legislativo a través de políticas sociales integradoras y de igualdad. (Pérez-Ugena, Martínez y Salas, 2011, p. 229).

En esta línea, un reciente estudio realizado por el Consejo Audiovisual de Cataluña sobre la campaña publicitaria de Navidad 2015-2016 ha revelado que un 34\% de los anuncios de juguetes que los niños y los adolescentes catalanes vieron a través de la pequeña pantalla en la última campaña de $\mathrm{Na}$ vidad contenían estereotipos de género, aunque el porcentaje sea menor con respecto a años anteriores.

A tenor de estos resultados, algunos autores como Espinar (2007) destacan la necesidad de que la televisión y los medios de comunicación en general se responsabilicen de su difusión de estereotipos y asuman su papel en el proceso de aprendizaje de niños y adolescentes:

Podemos preguntarnos si puede exigírsele a los medios de comunicación, y en concreto a la televisión, que se conviertan en motor del cambio social y que ejerzan tareas de autocontrol en cuanto a la transmisión de imágenes estereotipadas de hombres y mujeres [...] de forma que participen en el necesario proceso de cambio hacia una sociedad más igualitaria tanto para mujeres como para hombres. (2007, p. 134).

En relación a otras pantallas, tal como apunta Márquez (2013), el mundo de la tecnología, de la informática y de los videojuegos estuvo desde sus inicios asociado a lo masculino. Aún en la actualidad, los hombres siguen siendo mayoría en esta industria, tanto en la parte productiva como en el consumo «lo que no significa que el público femenino no disfrute de los videojuegos» (2013, p. 108), de hecho, un $45 \%$ de los jugadores españoles son mujeres (Aevi, 2014).

El reconocimiento de las mujeres como videojugadoras ha impulsado a la industria a poner en marcha ciertas estrategias con el fin de impulsar el consumo de videojuegos entre el público femenino. 
En la década de 1990 se produjo una división de los videojuegos en función del sexo del usuario: los juegos de color azul, dirigidos a un público masculino y relacionados con el combate y deporte, y los videojuegos rosas, pensados para mujeres y asociados a temas como la moda, la belleza y la cosmética. Una segmentación fruto de una lógica marketiniana, pero que cuenta con el apoyo de los padres, quienes en muchos casos resultan ser los compradores finales del producto:

\begin{abstract}
Se ha demostrado que las actitudes de los padres con respecto a estos juegos también refuerzan tales estereotipos. Por ejemplo, los diseñadores de KidCom, un juego creado específicamente para niñas de entre 7 y 12 años en Holanda, encontraron que a las chicas no les gustaba el color rosa pero a pesar de ello decidieron diseñarlo en este color porque cumplía con las expectativas de los padres. (Márquez, 2013, p. 108).
\end{abstract}

No obstante, según los datos aportados por la investigadora, este tipo de videojuegos dirigidos específicamente al público femenino fue un fracaso comercial. En contraposición, las mujeres mostraron una mayor disposición por aquellos títulos de género neutro.

En cuanto a la transmisión de características de género a través de los videojuegos, existen estudios que destacan un predominio importante de los personajes masculinos sobre los femeninos «y cuando aparecen suele ser representando un papel subordinado, como el personaje-tipo «damisela en apuros» (Márquez, 2013, p. 109). Un punto de inflexión supuso el lanzamiento de la saga Tomb Raider, protagonizada por el personaje femenino de Lara Croft, una representación de mujer opuesta a la imagen secundaria de títulos precedentes. Sin embargo «varios autores entienden que el paradigma de la mujer guerrera simbolizado por Lara Croft no desafía las representaciones tradicionales, sino que vuelve a caer en el estereotipo» (2013, p. 109). De todos modos, desde el sector también se idean y diseñan propuestas que presentan una imagen más realista de la mujer, como en los juegos Project Zero o Beyond Good and Evil, o de la promoción de la propia consola Wii, «de su innovadora interfaz, sus productos y campañas publicitarias a la hora de atraer a chicas, mujeres y otros segmentos de la población que hasta ahora habían sido ignorados por la industria» (Márquez, 2013, p. 112).

Esta investigación se centra concretamente en el niño como usuario de pantallas, por tanto, se trata de una audiencia totalmente inmersa en su proceso de formación personal. Existen múltiples teorías sobre cómo se adquieren los estereotipos de género durante la infancia; una corriente de pensamiento alude a los aspectos biológicos, otras a factores sociales y una tercera a elementos psicológicos.

No obstante, la tendencia actual es la de considerar todos estos aspectos dentro de un mismo marco teórico, «como la Teoría Social-Cognitiva del Desarrollo del Género y la Diferenciación en la que se considera que la evolución humana crea la estructura biológica sobre la cual actúan los factores psicológicos y sociales» (Bussey y Bandura, 1999, citado en Martínez-Reina y Vélez, 2009, p. 138). La interiorización de las diferencias de género tiene consecuencias educativas importantes ya que juegan un papel fundamental en las formas de pensar, interpretar y actuar de los niños, así como en las relaciones con sus iguales (Colás y Villaciervos, 2007).

Respecto a la relación de consumo e identidad de género en niños y adolescentes, estudios previos han concluido que las producciones televisivas han influido en la construcción de su identidad (Medrano, et al., 2009). Esta investigación amplía su campo de estudio a otras pantallas para mostrar si existen las mismas diferencias en función del sexo en el perfil de consumo de internet, videojuegos y también de televisión por parte de niños de último curso de primaria. 


\section{MetodologíA}

Con este trabajo en concreto se pretende comprobar si los escolares responden a las pautas de género que establece la industria de las pantallas en cuanto a la segmentación de contenidos para televisión, videojuegos e internet. Por ello se les preguntó de forma directa cuáles eran sus cadenas y programas de televisión, videojuegos y sitios web preferidos, una información que, tras ser tratada en SPSS, se segmentó en función del sexo para cotejar las diferencias entre los gustos de niños y niñas.

Los datos estadísticos que se exponen en este análisis forman parte de una investigación más amplia recogida en la tesis doctoral La infancia ante las pantallas: Análisis del consumo de medios audiovisuales (Tv, videojuegos e internet) entre los niños gallegos de último curso de primaria en 2010 (Feijoo, 2015), en la que se profundizó en los usos que los escolares daban a las pantallas citadas.

Para esta investigación se recurrió a la metodología cuantitativa de la encuesta autoadministrada entre individuos de 11 a 12 años que cursaba $6^{\circ}$ de primaria. Según datos del Instituto Nacional de Estadística en el momento de realizar el trabajo de campo (2010) la población gallega entre los 11 y los 12 años ascendía a 41.889 personas (21.513 hombres, 20.376 mujeres) repartidos en 898 centros educativos públicos y privados. Teniendo en cuenta el universo definido, para un índice de confianza del $95,5 \%$ con un margen de error de $+/-2,5 \%$ (varianza $\mathrm{P}=\mathrm{Q}=50$ ), la muestra para ser representativa, debía estar formada por 1.542 individuos.

Se empleó el cuestionario, instrumento básico de la observación por encuesta (Sierra Bravo, 2001) recurriendo en este caso al cuestionario simple que, de acuerdo a los parámetros expuestos, se repartió en un total de 77 colegios públicos y privados, consiguiendo una muestra final de 2.202 escolares. Aunque en la encuesta los datos se adquieren de forma indirecta (los resultados se obtuvieron a partir de las respuestas dadas por los niños), su capacidad para abarcar un amplio abanico de cuestiones sobre una muestra los suficientemente representativa, la convirtieron en el método más idóneo para esta investigación.

El cuestionario contemplaba una batería de 23 preguntas que buscaban conocer la relación de los niños gallegos con los medios audiovisuales. Consecuentemente, dichas cuestiones se estructuraron en tres bloques temáticos, cada uno referido a una pantalla (televisión, videojuegos e internet) en los que se preguntó sobre el tiempo dedicado y los contenidos consumidos, datos segmentados por sexo, tipo de colegio y hábitat.

\section{RESUltados}

La información estadística se presenta distribuida en tres apartados, uno para cada pantalla analizada en los que se muestran las preferencias de los niños segmentadas por sexo en torno al consumo de televisión (cadenas, formatos y programas), de videojuegos (géneros y títulos) y de internet (sitios web y redes sociales).

\subsection{TELEVISIÓN}

\subsubsection{CADENAS DE TV}

En lo que respecta a la oferta televisiva en abierto, Disney Channel (75,1\%), Antena Neox $(36,0 \%)$ y Clan TV $(20,0 \%)$ fueron las temáticas predilectas por los más pequeños; sin llegar al 20\% siguieron Teledeporte (11,1\%), FDF (8,7\%), Gol TV (7,4\%) y 40 latino $(6,6 \%)$. Otras cadenas como Nova, La Siete, CNN o Intereconomía lograron una penetración inferior al 5\%.

En cuanto a la oferta generalista, más de la mitad de la muestra (58,7\%) seleccionó Antena 3, el resto optó por Cuatro (32,4\%), La Sexta (20,8\%), Telecinco (13,8\%), TVE $(9,2 \%)$ y TVE2 $(2,9 \%)$. En 
lo que respecta a la TVG, cerca de un 9\% de los niños gallegos encuestados la marcaron como una de sus favoritas; TVG2 fue seleccionada por un $1,9 \%$.

Tabla 1. Cadenas de TV preferentes

\begin{tabular}{|l|l|l|l|}
\hline Cadenas & \multirow{2}{*}{ Total $(\%)$} & \multicolumn{3}{|c|}{ Segmentación por sexo (\%) } \\
\cline { 3 - 4 } & & Niña & Niño \\
\hline Antena3 & 58,7 & 67,2 & 51,6 \\
\hline Antena Neox & 36,0 & 41,0 & 34,4 \\
\hline Antena Nova & 3,9 & 5,9 & 2,6 \\
\hline Canal Promo & 0,0 & 0,0 & 0,1 \\
\hline Cinco Shop & 0,4 & 0,2 & 0,4 \\
\hline CNN & 0,5 & 0,4 & 0,4 \\
\hline Cuatro & 32,4 & 27,4 & 37,7 \\
\hline Disney Channel & 75,1 & 87,2 & 61,9 \\
\hline FDF Telecinco & 8,7 & 4,3 & 12,1 \\
\hline Gol TV & 7,4 & 1,0 & 12,5 \\
\hline Intereconomía & 0,1 & 0,0 & 0,3 \\
\hline La Sexta & 20,8 & 11,5 & 29,5 \\
\hline La Siete & 1,8 & 2,2 & 1,8 \\
\hline Set en Veo & 0,2 & 0,2 & 0,2 \\
\hline Telecinco & 13,8 & 19,1 & 7,9 \\
\hline Teledeporte & 11,1 & 4,5 & 17,7 \\
\hline TVE1 & 9,2 & 8,9 & 8,3 \\
\hline TVE2 & 2,9 & 2,9 & 3,6 \\
\hline TVE 24horas & 0,5 & 0,4 & 0,9 \\
\hline TVG & 8,9 & 9,2 & 8,8 \\
\hline TVG2 & 1,9 & 1,4 & 2,7 \\
\hline Tvs Locales & 0,1 & 0,4 & 0,0 \\
\hline Tienda en Veo & 0,1 & 0,1 & 0,0 \\
\hline Veo & 0,6 & 0,6 & 0,6 \\
\hline 40 Latino & 6,6 & 9,7 & 3,6 \\
\hline Clan TV & 19,5 & 17,6 & 21,3 \\
\hline & Fuente: Elaboración propia. & \\
\hline
\end{tabular}

Si se diferencia por sexo, determinadas cadenas son más afines a los niños y otras a las niñas. Los resultados evidenciaron que las temáticas de deporte como Teledeporte o Gol TV despertaron más interés entre los niños, así como FDF. Las niñas expresaron mayor preferencia por temáticas como Nova o 40 Latino. El análisis también mostró que Neox y Disney Channel tienden a tener un perfil más femenino, al contrario de Clan TV, con una cierta tendencia masculina.

En lo que respecta a la oferta generalista, si Cuatro y La Sexta tuvieron más afinidad con los varones, Antena 3 y Telecinco son más atractivas para las mujeres; la televisión estatal pública, TVE, interesó por igual a hombres que mujeres. En cuanto a la oferta autonómica gallega, tanto niños como niñas prefieren por igual la primera cadena, aunque se distinguió una cierta tendencia de los niños hacia la segunda cadena (TVG2). 


\subsubsection{FORMATOS Y PROGRAMAS DE TV}

Los dibujos animados resultaron el formato televisivo predilecto de los niños encuestados: un $36,1 \%$ de todas las propuestas mencionadas resultó ser algún dibujo animado. Las series extranjeras $(22,4 \%)$ y las españolas $(11,4 \%)$ completan la tipología de programas preferida por estos escolares.

La telenovela $(8,0 \%)$ y el talk show $(6,2 \%)$ también consiguieron niveles de aceptación interesantes; en un escalafón inferior se posicionan las retransmisiones deportivas $(3,1 \%)$, los concursos $(3,0 \%)$, los programas de telerrealidad $(2,9 \%)$ y de divulgación $(2,3 \%)$.

Tabla 2. Formatos de TV favoritos

\begin{tabular}{|l|l|l|l|}
\hline Formatos televisivos & \multirow{2}{*}{ Total (\%) } & \multicolumn{3}{|l|}{ Segmentación por sexo $(\%)$} \\
\cline { 3 - 4 } & & Niña & Niño \\
\hline Cine/películas & 0,4 & 0,6 & 1,4 \\
\hline Concursos & 3,0 & 7,9 & 6,8 \\
\hline Dibujos animados & 36,1 & 49,4 & 75,4 \\
\hline Documental & 0,5 & 0,9 & 2,0 \\
\hline Informativos & 0,8 & 1,9 & 2,9 \\
\hline Magazine & 0,3 & 1,1 & 0,9 \\
\hline Programas de deporte & 1,8 & 0,9 & 9,1 \\
\hline Retransmisión deportiva & 3,1 & 2,5 & 14,1 \\
\hline Serie extranjera & 22,4 & 57,8 & 28,7 \\
\hline Serie española & 11,4 & 27,5 & 20,5 \\
\hline Talk show & 6,2 & 13,3 & 21,8 \\
\hline Telenovela & 8,0 & 39,0 & 4,2 \\
\hline Telerrealidad & 2,9 & 11,8 & 2,9 \\
\hline Musicales & 0,2 & 0,6 & 0,5 \\
\hline Serie documental & 0,7 & 1,8 & 2,4 \\
\hline Divulgativos & 2,3 & 5,1 & 7,1 \\
\hline & Fuente: Elaboración propia. & \\
\hline
\end{tabular}

$\mathrm{Al}$ segmentar las respuestas por sexo, la disparidad de gustos fue significativa. Las niñas se decantaron claramente por las series tanto nacionales como extranjeras, las telenovelas, los programas de telerrealidad y por los concursos. Por su parte, los niños fueron los máximos defensores de los dibujos animados, talk show, retransmisiones y programas deportivos y de los divulgativos. Los informativos, el cine y los documentales lograron mayor aceptación entre el público masculino.

Tras comprobar la diversidad de respuestas en relación a los programas de TV favoritos, se optó por diseñar una short list que contuviese las diez propuestas más citadas por la muestra. De la lista establecida, casi la mitad de los niños $(47,9 \%)$ marcó como favorita alguna serie juvenil extranjera, tal como 'Hannah Montana', 'Sunny entre estrellas', 'Hotel dulce hotel: las aventuras de Zack y Cody', 'Los Magos de Waverly Place', 'El Club de la Herradura' y 'Jonas' (curiosamente todas ellas emitidas en Disney Channel). Un lugar preferente dentro de sus gustos también lo ocupa la serie animada 'Los Simpson', recordada por un 40,8\%. Dos de cada diez niños optaron por la telenovela 'Patito Feo', de igual modo que un $17,8 \%$ por los dibujos 'Phineas y Ferb' y un 16,9\% por otras propuestas animadas como 'Shin Chan', 'Naruto', 'Pokémon' o ‘Bob Esponja'. En medio de la tabla se encuentra 'El Hor- 
miguero', con formato de talk show y favorito para un 15,7\% de la muestra. Las series españolas 'Física o Química' (15,2\%) y 'El Internado' (12,3\%), las ficciones animadas 'Padre de Familia' y 'American Dad' $(12,3 \%)$ junto con las retransmisiones y/o programas sobre fútbol $(7,6 \%)$ completan esta short list.

Tabla 3. Programas de TV favoritos

\begin{tabular}{|l|l|l|l|}
\hline Programas televisivos & \multirow{2}{*}{ Total (\%) } & \multicolumn{2}{l|}{ Segmentación por sexo (\%) } \\
\cline { 3 - 4 } & & Niña & Niño \\
\hline Los Simpson & 40,8 & 34,4 & 49,2 \\
\hline Phineas y Ferb Shin Chan, Naruto, & 16,9 & 7,9 & 19,6 \\
\hline $\begin{array}{l}\text { Otros dibujos animados: } \\
\text { Pokemon, Bob Esponja }\end{array}$ & & & 23,2 \\
\hline Padre de Familia/American Dad & 12,3 & 4,7 & 15,8 \\
\hline El Internado & 10,0 & 13,3 & 7,2 \\
\hline Física o Química & 15,2 & 18,9 & 12,0 \\
\hline Patito Feo & 20,6 & 37,3 & 3,8 \\
\hline $\begin{array}{l}\text { Series juveniles extranjeras: Hannah Montana, Sunny, } \\
\text { Zack y Cody, Los magos de WG, El club Herradura, } \\
\text { Jonas }\end{array}$ & 47,9 & 50,1 & 17,4 \\
\hline El Hormiguero & 15,7 & 11,0 & \\
\hline Fútbol & 7,6 & 1,9 & 14,1 \\
\hline
\end{tabular}

Fuente: Elaboración propia.

Las niñas y niños tienen preferencias bastante diferenciadas. Las primeras optaron principalmente por las series juveniles extranjeras y por 'Patito Feo'. Los niños se inclinaron en mayor medida por las emisiones de dibujos animados, 'El Hormiguero' y por el fútbol. 'El Internado' y 'Física o Química' tuvieron más aceptación entre el público femenino.

\subsection{VIDEOJUEGOS}

\subsubsection{GÉNEROS Y TÍTULOS}

Los resultados revelaron que los videojuegos de plataforma $(23,6 \%)$ y de deporte $(22,3 \%)$ fueron los más mencionados, seguidos de los juegos de acción (12,2\%) y de simulación social (10,2\%). También obtuvieron representación, aunque en menor medida, los géneros de aventuras gráficas $(6,4 \%)$, de lucha y los juegos de utilidad diaria $(7,7 \%)$. 
Tabla 4. Géneros de videojuegos más citados

\begin{tabular}{|l|l|l|l|}
\hline Géneros de videojuegos & \multirow{2}{*}{ Total (\%) } & \multicolumn{2}{|l|}{ Segmentación por sexo (\%) } \\
\cline { 3 - 4 } & & Niña & Niño \\
\hline Acción & 12,2 & 2,3 & 21,7 \\
\hline Arcade/pasatiempos & 2,2 & 4,5 & 0,6 \\
\hline Aventuras gráficas & 6,4 & 4,2 & 8,1 \\
\hline Conducción/carreras & 4,6 & 0,9 & 7,3 \\
\hline Deporte & 22,3 & 8,1 & 33,0 \\
\hline Educativo & 0,3 & 0,0 & 0,4 \\
\hline Simulación social & 10,2 & 14,6 & 7,4 \\
\hline Inteligencia/habilidad mental & $5,7 \%$ & 9,5 & 3,0 \\
\hline Lucha & 4,9 & 2,0 & 6,1 \\
\hline Plataforma & 23,6 & 37,8 & 11,4 \\
\hline Rol & 0,1 & 0,0 & 0,2 \\
\hline $\begin{array}{l}\text { Utilidad diaria } \\
\text { (cocina, moda, cuidados niños...) }\end{array}$ & 7,7 & 16,0 & 0,6 \\
\hline
\end{tabular}

Fuente: Elaboración propia.

En relación a los géneros de los videojuegos, mientras que las niñas optaron más por los juegos de plataforma, de utilidad diaria, simulación social y de inteligencia/habilidad mental, los niños prefirieron más que las chicas los títulos de deporte, de acción y de aventuras gráficas.

En la tabla 5 se pueden consultar los videojuegos más nombrados por los escolares encuestados. Destacan especialmente los juegos de la saga Mario Bros. (27,4\%) y las distintas versiones del FIFA $(20,2 \%)$. Los videojuegos de simulación social 'Los Sims' y 'Animal Crossing' y el de acción 'Gran Theft Auto’ (GTA) completan la lista de los cinco títulos más populares entre los menores que participaron en esta investigación.

Tabla 5. Títulos de los videojuegos preferidos

\begin{tabular}{|l|l|l|l|}
\hline Videojuegos favoritos & \multirow{2}{*}{ Total (\%) } & \multicolumn{2}{|l|}{ Segmentación por sexo (\%) } \\
\cline { 3 - 4 } & & Niña & Niño \\
\hline Animal Crossing & 10,4 & 18,9 & 1,6 \\
\hline Assassins Creed & 1,3 & 0,3 & 2,6 \\
\hline Brain Training & 1,3 & 2,0 & 0,2 \\
\hline El profesor Hayton y la Caja de Pandora & 1,8 & 3,4 & 0,7 \\
\hline FIFA & 20,2 & 3,4 & 33,5 \\
\hline GTA (Gran Theft Auto) & 11,8 & 2,3 & 21,5 \\
\hline Gran Turismo & 2,1 & 0,3 & 4,0 \\
\hline PES (Pro Evolution Soccer) & 9,5 & 0,3 & 17,1 \\
\hline Serie Mario (Mario Kart, Mario Bros) & 27,4 & 44,4 & 12,2 \\
\hline The Sims & 12,6 & 24,0 & 3,5 \\
\hline Zelda & 1,6 & 0,8 & 3,0 \\
\hline
\end{tabular}

Fuente: Elaboración propia.

Al segmentar por sexo esta lista de los videojuegos favoritos, los gustos divergen bastante. En el caso de los varones, sus juegos preferidos son dos títulos de fútbol, FIFA y 'Pro Evolution Soccer' 
(PES), y uno de acción, GTA; las niñas, por su parte, se decantaron por los videojuegos de la saga de Mario Bros., 'Los Sims' y 'Animal Crossing'.

\subsection{INTERNET}

\subsubsection{SITIOS WEB}

Catalogados los resultados se pudo extraer una lista concreta de los principales portales web a los que los niños acostumbran acceder. El contenedor de vídeos YouTube fue el servicio más citado, recordado de forma voluntaria por casi cinco de cada diez niños encuestados, seguido del programa de mensajería instantánea MSN Messenger (39,1\%) y de la página web de juegos Minijuegos.com $(35,7 \%)$. El buscador Google, otros portales de juegos virtuales como Juegos.com, Juegosjuegos.com o Sésamo, los servicios de correo de Gmail, Yahoo y Hotmail y la enciclopedia online Wikipedia completan la serie de los espacios web preferidos.

Tabla 6. Portales web más visitados

\begin{tabular}{|l|l|l|l|}
\hline Páginas/servicios web más nombrados & \multirow{2}{*}{ Total (\%) } & \multicolumn{2}{|l|}{ Segmentación por sexo (\%) } \\
\cline { 3 - 4 } & & Niña & Niño \\
\hline Correo Gmail/Yahoo/Hotmail & 7,5 & 9,7 & 4,8 \\
\hline Google & 16,4 & 16,9 & 15,8 \\
\hline Juegos.com / Juegosjuegos.com & 14,1 & 17,4 & 12,2 \\
\hline Messenger & 39,1 & 47,4 & 31,5 \\
\hline Minijuegos & 35,7 & 20,3 & 49,4 \\
\hline Sésamo & 1,2 & 1,0 & 0,6 \\
\hline Wikipedia & 3,5 & 3,2 & 3,5 \\
\hline YouTube & 46,1 & 45,7 & 47,2 \\
\hline
\end{tabular}

Fuente: Elaboración propia.

$\mathrm{Al}$ diferenciar por sexo las preferencias, los varones se inclinaron en mayor medida por el portal Minijuegos.com, mientras que las mujeres por la aplicación Messenger, por el servicio de correo de Gmail/Yahoo/Hotmail y por las páginas Juegos.com, Juegosjuegos.com o Sésamo (también de juegos virtuales). Aunque se analiza más adelante en un epígrafe concreto, YouTube logró una penetración mayor entre el público masculino.

\subsubsection{REDES SOCIALES}

$\mathrm{Al}$ analizar el nivel de penetración de las redes sociales, los niños también tienen sus favoritas. De entre las opciones de respuesta propuestas en el cuestionario, un mayor número de seguidores $(24,9 \%)$ seleccionó Tuenti, seguida de Facebook $(13,5 \%)$ y de las redes sociales fotográficas Metroflog $(10,2 \%)$ y Fotolog (5,2\%).

De entre las opciones propuestas por el propio encuestado en la categoría 'Otros', un 36,4\% de la muestra citó de forma voluntaria la aplicación de mensajería Messenger, de lo que se deduce que los escolares la consideran una red social. Tanto es así que este servicio de Microsoft se erigió como la 'red social' más popular entre los niños gallegos. El portal para un público infantil y adolescente, Habbo.es $(4,2 \%)$, y los servicios de Yahoo $(1,0 \%)$ completan el registro de propuestas más citadas. 
Tabla 7. Redes sociales más empleadas

\begin{tabular}{|l|l|l|l|}
\hline Redes sociales más empleadas & \multirow{2}{*}{ Total (\%) } & \multicolumn{2}{|l|}{ Segmentación por sexo (\%) } \\
\cline { 3 - 4 } & & Niña & Niño \\
\hline Tuenti & 24,9 & 25,7 & 23,2 \\
\hline Facebook & 13,5 & 13,7 & 14,4 \\
\hline Fotolog & 5,2 & 5,7 & 5,3 \\
\hline Metroflog & 10,2 & 12,8 & 9,2 \\
\hline *MSN Messenger & 36,4 & 39,1 & 32,1 \\
\hline *Yahoo & 1,0 & 0,8 & 0,9 \\
\hline *Habbo & 4,2 & 3,4 & 5,0 \\
\hline Otras RRSS citadas & 3,3 & 2,8 & 2,9 \\
\hline *Propuestas por los encuestados \\
\hline
\end{tabular}

Fuente: Elaboración propia.

Ser niño o niña no implica grandes diferencias a la hora de escoger una red social u otra. Levemente se pudo apreciar cómo las mujeres se inclinaron en mayor medida por Messenger y Metroflog; los niños, por su parte, mostraron más afinidad que las niñas por el portal Habbo.

\section{DISCUSIÓN Y CONCLUSIONES}

A tenor de los resultados obtenidos parece demostrarse que el sexo condicionó en gran medida las respuestas recibidas, sobre todo en la selección de las cadenas y programas televisivos y de los videojuegos. En relación a estas dos pantallas, los encuestados no citaron ningún contenido que fuese común a las preferencias de ambos sexos. En el gráfico 1 se puede observar su disparidad de gustos audiovisuales. Esta diferencia deja de ser tan evidente en la red y, aunque igualmente aparecen ciertas preferencias en función del sexo (sobre todo relacionadas con el uso del Messenger y del correo electrónico), los varones y las mujeres visitan por igual los portales web de YouTube, Wikipedia o de páginas de juegos online.

Gráfico 1. Programas de TV, videojuegos y sitios web favoritos segmentados por sexo

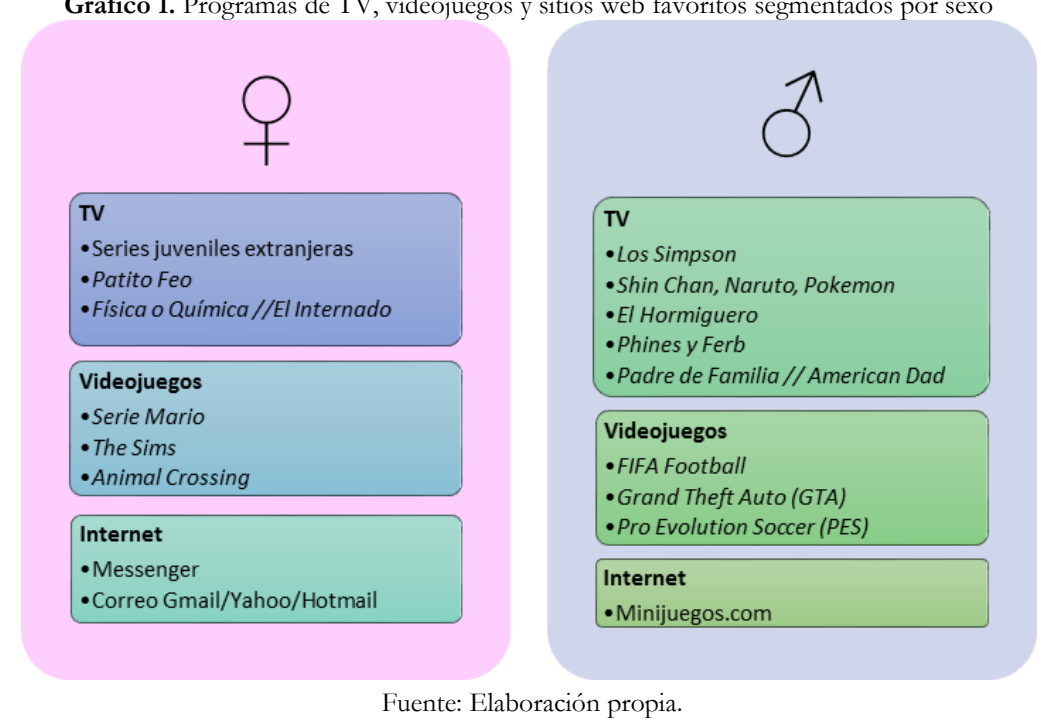


Resulta interesante comprobar las diferencias en cuanto a contenidos según la pantalla de la que se trate. Así, los datos parecen indicar que los encuestados tienden a relacionar los contenidos con la concepción de género que establece la industria audiovisual con mayor intensidad ante el televisor y la videoconsola que en internet. Aun así, hay autores como Abuin Vences (2009) que apuntan que, a pesar de todo, se está reduciendo cada vez más la distancia entre el universo masculino y el universo femenino, pero aunque la sociedad avanza, el discurso publicitario va todavía un paso por detrás, y se sirve muchas veces de imágenes y mensajes vinculados a determinados roles sociales para vender productos.

Una de las posibles causas que justifiquen los resultados obtenidos puede estar relacionada con el poder de influencia de los agentes sociales, especialmente de los padres, que suelen influir en el uso que hacen sus hijos de las dos primeras pantallas, siendo más sencillo su mediación en el consumo de contenidos de los pequeños. En este sentido, la publicidad y los medios de comunicación puedan aportar una contribución importante al cambio de actitudes, erradicando los estereotipos ligados al sexo, porque estos constituyen un factor de desigualdad (Conferencia de Pekín, 1995). No obstante, como destaca Del Bravo (2002), si se examinan las mentalidades y formas de vida que imperan en Occidente, se detecta «una cultura de muerte», sustentada por tres ideas: el relativismo, la concepción de los derechos humanos y el consumismo. Consecuentemente, se plantean unos retos para crear otros modos de pensar y de vivir más conformes con la dignidad de la persona y con la cultura de la vida

Siguiendo con los resultados de esta investigación, el uso de internet en los hogares implica una brecha digital que provoca la coexistencia de unos padres inmigrantes digitales con hijos nativos digitales cuyo dominio de la tecnología supera al de sus progenitores, de ahí que su poder de influencia de los mayores en la selección de contenidos sea menor y los niños puedan escoger más espontáneamente sus webs de referencia.

No obstante, este planteamiento se presenta como una posible hipótesis que requeriría un estudio mucho más profundo en el que se pudiese comprobar la mediación parental en la selección de contenidos a través de las pantallas. En esta investigación no se puede concluir que en las respuestas dadas por los niños exista una cierta influencia social, bien pudieron ser fruto de una elección totalmente libre por parte de los encuestados, de ahí que se insista en que una futura línea de investigación pueda estar encaminada a comprobar dicha influencia parental en la selección de contenidos audiovisuales.

De todos modos, sí que parece evidenciarse que el perfil de consumo de los niños, por lo menos en televisión y con los videojuegos, contribuye a definir el significado de género transmitido por medios de masas y otros agentes culturales.

\section{BIBLIOGRAFÍA}

Abuin Vences, N. (2009). Publicidad, roles sociales y discurso de género. En Actes de Congènere: la representació de gènere a la publicitat del segle XXI, 1-12.

Asociación española de videojuegos. (2014). Padres y videojuegos hoy. [En línea]. Recuperado el 23 de octubre de 2016 en http:/ $/$ www.aevi.org.es/index.php?option $=$ com mtree\&task $=$ att download\&link id $=71 \& c f$ id $=$ $\underline{30}$

Belmonte, J., y Guillamón, S. (2008). Co-educar la mirada contra los estereotipos de género en TV. Comunicar, 16(31), 115-120. Doi: http://dx.doi.org/10.3916/c31-2008-01-014

Burggraf, J. (2001). ¿Qué quiere decir género?: en torno a un nuevo modo de hablar. San José (Costa Rica): Ediciones Promesa. 
Colás, P., y Villaciervos, P. (2007). La interiorización de los estereotipos de género en jóvenes y adolescentes. Revista de Investigación Educativa, 25(1), 35-58.

Conferencia Mundial sobre la Mujer. IV Conferencia, 1995, Pekín.

Consell de l'Audiovisual de Catalunya. (2016). La representació dels estereotips de gènere en la publicitat de joguines durant la campanya de Nadal 2015-2016. [En línea]. Recuperado el 15 de octubre de 2016 en http://www.cac.cat/pfw files/cma/actuacions/Acord 102016 CAT.pdf

Del Bravo, M. A. (2002). La mujer en la Historia. Madrid. Encuentro. 33-40.

Del Moral, M. E., Villalustre, L., y Neira, M. R. (2010). La asimilación cognitiva infantil de los estereotipos representados a través de los dibujos animados. Observatorio (OBS), 4(3), 89-105. doi: http://dx.doi.org/10.7458/obs432010381

Espinar, E. (2006). Imágenes y estereotipos de género en la programación y en la publicidad infantil. Análisis cuantitativo. Revista Latina de Comunicación Social, 61. [En línea]. Recuperado el 17 de octubre en http://www.ull.es/publicaciones/latina/200614Espinar_Ruiz.htm

Espinar, E. (2007). Estereotipos de género en los contenidos audiovisuales infantiles. Comunicar, 15(29), 129-134.

Feijoo, Beatriz. (2015). La infancia ante las pantallas. Análisis del consumo de medios audiovisuales (TV, videojuegos e internet) entre los niños gallegos del último curso de primaria (11-12 años) en 2010 (tesis doctoral). Universidade de Vigo, Pontevedra.

García-Guardia, M. L., y Marcos-Molano, M. M. (2004). La construcción de personajes en el videojuego SIMS 2. Revista ICONO14. Revista científica de Comunicación y Tecnologías emergentes, 4, 1-13.

Martínez-Reina, M. C., y Vélez, M. (2005). Estereotipos de género en el juego y en el ocio tecnológico interactivo. En Actas del VI Congreso Internacional de Interacción Persona-Ordenador, interacción, 1-8.

Martínez-Reina, M. C., y Vélez, M. (2009). Actitud en niños y adultos sobre los estereotipos de género en juguetes infantiles. CIENCLA ergo-sum, 16(2), 137-144.

Márquez, I. (2013). Roles, estereotipos y usos: género y videojuegos. Telos: Cuadernos de comunicación e innovación, 96, 106-114.

Medrano, C., Aierbe, A., y Orejudo, S. (2009). El perfil de consumo televisivo en adolescentes: diferencias en función del sexo y estereotipos sociales. Infancia y Aprendizaje, 32(3), 293-306. doi: http://dx.doi.org/10.1174/021037009788964150

Pérez-Ugena, Á., Martínez Pastor, C. E., y Salas Martínez, Á. (2011). Los estereotipos de género en la publicidad de los juguetes. Ámbitos, 20, 217-235.

Rodríguez Dorantes, C. (1997). Género y medios masivos de comunicación: una propuesta de investigación. En Coloquio Generación McLuban: investigadores de la Comunicación en los treinta y tantos años, Universidad Intercontinental, 22 al 24 de mayo de 1997.

Ruiz, C. (2012). Estereotipos de mujeres en películas infantiles. Influencia en la personalidad de los niños. Creación y Producción en Diseño y Comunicación, 46, 17-19.

Sierra Bravo, R. (2001). Técnicas de Investigación Social. Teorias y ejercicios. Madrid: Ediciones Paraninfo S.A. 